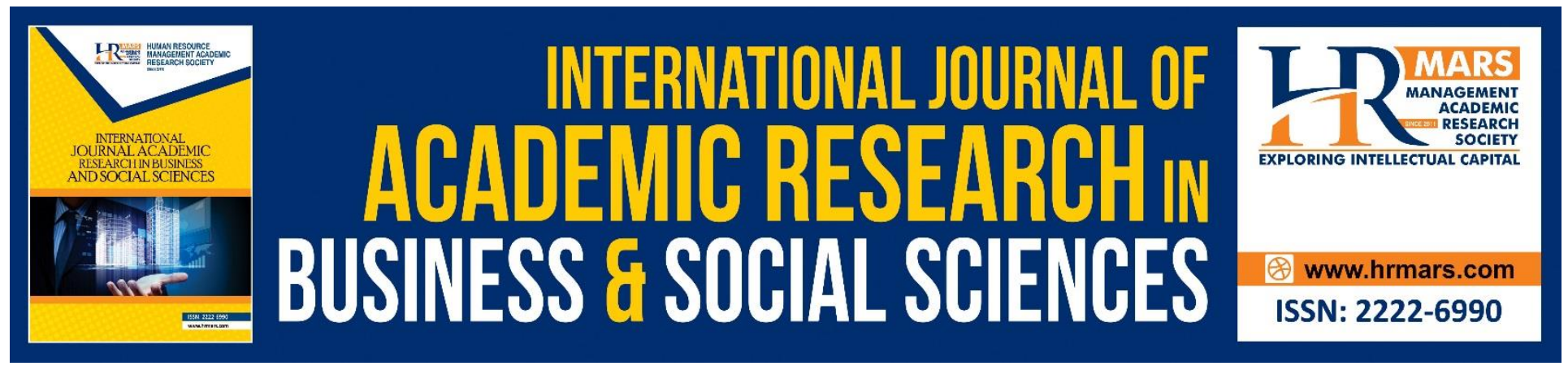

\title{
Regulatory Framework for Online Businesses in Malaysia
}

\author{
Maheran Makhtar \\ Farhanin Abdullah Asuhaimi
}

To Link this Article: http://dx.doi.org/10.6007/IJARBSS/v9-i3/5703

DOI: $\quad 10.6007 /$ IJARBSS/v9-i3/5703

Received: 02 Feb 2019, Revised: 17 Feb 2019, Accepted: 30 Feb 2019

Published Online: 03 March 2019

In-Text Citation: (Makhtar \& Asuhaimi, 2019)

To Cite this Article: Makhtar, M., \& Asuhaimi, F. A. (2019). Regulatory Framework for Online Businesses in Malaysia. International Journal of Academic Research in Business and Social Sciences, 9(3), 427-438.

Copyright: (c) 2019 The Author(s)

Published by Human Resource Management Academic Research Society (www.hrmars.com)

This article is published under the Creative Commons Attribution (CC BY 4.0) license. Anyone may reproduce, distribute, translate and create derivative works of this article (for both commercial and non-commercial purposes), subject to full attribution to the original publication and authors. The full terms of this license may be seen at: http://creativecommons.org/licences/by/4.0/legalcode

Vol. 9, No. 3, 2019, Pg. 427 - 438

http://hrmars.com/index.php/pages/detail/IJARBSS

JOURNAL HOMEPAGE

Full Terms \& Conditions of access and use can be found at http://hrmars.com/index.php/pages/detail/publication-ethics 


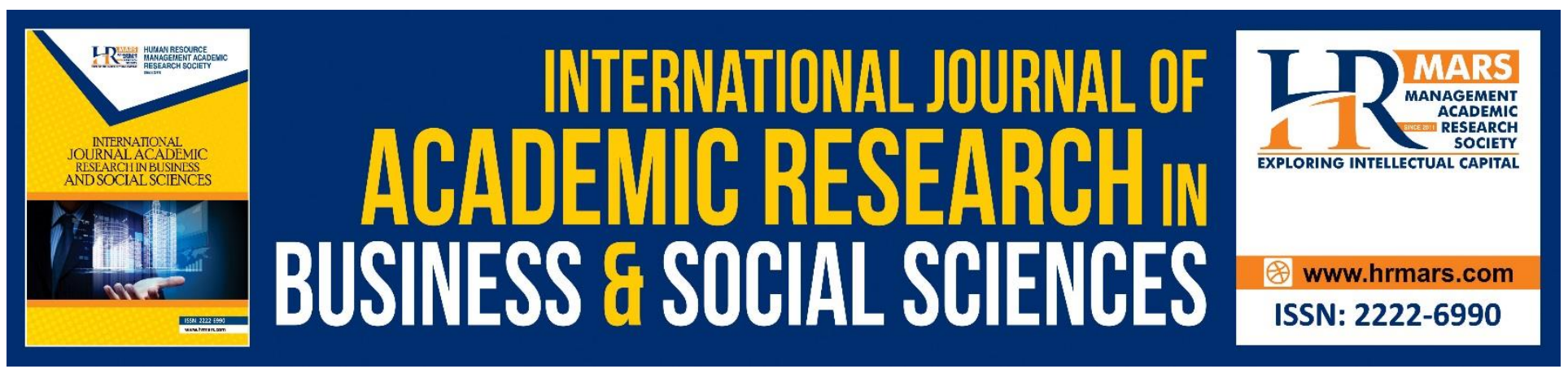

\title{
Regulatory Framework for Online Businesses in Malaysia
}

\author{
Maheran Makhtar \\ Universiti Sultan Zainal Abidin, Department of Law, Faculty of Law and International Relations, \\ 21300 Kuala Nerus, Terengganu, Malaysia \\ Farhanin Abdullah Asuhaimi \\ Universiti Sultan Zainal Abidin, Department of Law, Faculty of Law and International Relations, \\ 21300 Kuala Nerus, Terengganu, Malaysia
}

\begin{abstract}
Background: Online business becomes a very popular trending in Malaysia especially in selling goods and services. Clothing and personal accessories are among the many types of businesses which are commonly carried up via Internet. Some online businesses' owners embark on this business for a short period of time while some others rely totally on this medium in marketing their products and services. Nevertheless, there are online users who misused this medium by committing unlawful activities such as internet fraud, internet scams and misuse of confidential information. Objective: This research intends to list down all the existing e-commerce laws in Malaysia and highlight major legal issues which may arise from online businesses and how these issues are regulated in order to ensure the parties involved are protected. The research would also examine whether the regulations are in line with Islamic perspective in Malaysia. Results: In Malaysia, there is currently no regulatory framework for online businesses. Conclusion: There is a need to draft and enact ONE comprehensive legislation on electronic commerce, its protection to consumer as well as the buyer and the penalty for those who against the law.
\end{abstract}

\section{Introduction}

Electronic or digital commerce, commonly known as e-commerce, is where the buying and selling of products or services is conducted over electronic systems such as the Internet and other computer networks. E-commerce by way of blog businesses becomes very popular among the societies nowadays. The trend become increasing from year to year. This has been caused by several factors such as availability of internet, affordability town personal computers and increase in computer ability (Ding, 1999). The easy access of internet also contributes to this. In Malaysia, the number of internet users as at January 2017 is 22 million compared to last year, the number is 21 million. 
Because of the increasing trend, statista.com stated that this figure is projected to grow to 23.41 million in 2022 (Statista, n.d.).

Online businesses bring many benefits to both traders and consumers. For traders, online transaction brings greater efficiency, increased responsiveness and reduces cost. It enables small companies and newcomers on the market to extend their reach far beyond what was previously possible (Rachagan.S, 1997). Consumers also stand to gain from wider choice, increased availability of specialized products, more comprehensive product information, lower costs and more responsive services.

The consumers can buy almost anything at any time and form any part of the world without leaving their homes. Everything can be made online without any headache to think on the fuel price, parking space, and tantrum of the toddler. In fact, some e-consumers allure with the concept of "bringing stores to shoppers-not shoppers to stores" (Parsons, 2002).

\section{Methodology}

The authors adopt statutory analysis approach which involved identifying legal issues based on the statutory interpretation and rules of laws.

\section{Discussion}

\section{The Legal Framework}

\section{A. Contracts Act 1950}

The fundamentals of contract are dealt with under Contracts Act 1950. Under the Act, a contract is formed when there is an offer, acceptance and consideration. An offer under section 2(a) of the Contracts Act 1950 takes place when "one person signifies to another his willingness to do or to abstain from doing anything". In e-commerce transaction, an offer happens when the online seller advertises his or her products or services through his or her internet platform. The offer can take place either in one-to-one situation or to a group. An offer can be made to a public at large (Peel, 2015). In the case of Carlill v Carbolic Smoke Ball Co [1893] 1 QB 256, the court acknowledged that the advertisement made in the newspaper was clearly an offer by the defendants as it was published that it might be read and acted on; the advertisement was address to all the public. Acceptance on the other hand acceptance takes place "when the person to whom the proposal is made signifies his assent thereto" [section 2(b) Contracts Act 1950]. It is a requirement that there must be a communication of acceptance and it has to come to the knowledge of the offeror. However, Lord Blackburn, in Brogden v. Metropolitan Ry. Co. (4) 2 B. \& Ad. 232, said that merely doing the acts indicated is an acceptance of the proposal.

\section{B. Sale of Goods Act 1957}

Clothing, household items, food or even pet could be transacted online. Section 2 of the Sale of Goods Act (SOGA) defines 'goods' as to man every kind of movable property other than actionable claims and money; and includes stock and shares, growing crops, grass and things attached to or forming 
part of the land which are agreed to be severed before sale or under the contract of sale. Contract to provide services are not covered under the Act.

Section 5 states that a contract of sale is formed when there is an offer to sell or buy at a certain price and acceptance to such offer. The goods may either be existing goods or future goods (section 6 ). In e-commerce transaction for example, the offer to sell food may be in a form of future goods where the seller offers to sell home-made food at a later date and requires a purchase order (acceptance) from the buyer. The contract of sale is a valid one even though its payment and delivery of goods is postponed (section 5). The Court of Appeal in the case of NGV Tech Sdn Bhd (appointed receiver and manager) (in liquidation) \& Anor v Kerajaan Malaysia [2017] 2 MLJ 522 held that the contract to buy two custom-made training vessels where its construction was monitored and the payments were made by stages until its completion was an unquestionably a contract for the sale of future goods within the meaning of the Sale of Goods Act.

Section 16 of Sale of Goods Act 1957 provides that there is an implied condition as to the quality and fitness of the goods. Condition is a stipulation essential to the main purpose of the contract, the breach of which gives rise to a right to treat the contract as repudiated (section 12). Section 41 provides that a buyer has to examine the goods delivered to him and if it is not previously examined, the buyer is not deemed to have accepted it.

\section{Consumer Protection Act 1999 \& Consumer Protection (Electronic Trade Transaction) Regulation 2012}

The Malaysia's Consumer Protection Act 1999 (CPA) is a piece of legislation enacted with the main objective to provide protection for consumers. This Act also establishes the Tribunal for Consumer Claims (Section 85, Part XII), an independent body operates under the Ministry of Domestic Trade, Co-Operatives and Consumerism. Section 3 of the Act defines consumer in two categories. The first category is a person who acquires or uses goods or services of a kind ordinarily acquired for personal, domestic or household purpose use or consumption; and the other category is a person who does not acquire or use the goods or services, or hold himself out as acquiring or using the goods or services, primarily for the purpose of (i) resupplying them in trade; (ii) consuming them in the course of a manufacturing process; or (iii) in the case of goods, repairing or treating, in trade, other goods or fixtures on land. The definition of 'goods' under this Act is wider than SOGA. The CPA defines 'goods' as goods attached to, or incorporated in, any real or personal property; animals, including fish; vessels and vehicles; utilities; and trees, plants and crops whether on, under or attached to land or not. There are broad range of protection to consumers under the Act. The CPA covers misleading and deceptive conduct, false representation and unfair practice in respect of the goods, price and advertisement, rights safety of goods and services, rights in respect of implied guarantee as to quality, fitness and compliance with description and sample, rights against suppliers and manufacturers, guarantees in respect of supply of services and product liability. Originally, CPA protection does not extend to e-commerce business. However in 2007, the Act was amended to include electronic trading in its coverage.

The Consumer Protection (Electronic Trade Transaction) Regulation 2012 (2012 Regulation) was nevertheless introduced to provide more safeguard for e-commerce business. The 2012 Regulation requires the online sellers to firstly, disclose the business information on the website or online 
marketplace where the business is conducted (section 3). The matters to be disclosed are the names of the business (name of the owner, business or company), the registration number of the business or company, if applicable, he email address and telephone number, or address of the online business supplier, a description of the main characteristics of the goods or services, the full price of the goods or services, including transportation costs, taxes and any other costs, the method of payment, the terms and conditions of the sale and the estimated time of delivery of the goods or services to the buyer (Schedule, regulation 3). Secondly, the online seller must provide appropriate means to enable the buyer to rectify any errors prior to the confirmation of the order made by the buyer and lastly, the online seller must acknowledge receipt of the order to the buyer without undue delay (section 4). The requirement to state a correct description of goods advertised can also be found in section 4 of the Trade Descriptions Act 1972.

\section{Personal Data Protection Act 2010}

In Malaysia, the Personal Data Protection Act 2010 (PDPA2010) provides a regulatory framework for the processing of personal data in commercial transactions including electronic commerce and business transactions. The Act provides for provisions to combat credit card fraud, identity theft and selling of personal data without customer consent, and to build consumer confidence (Kandiah, 2016). 'Personal data' is defined as "personal data" means any information in respect of commercial transactions, which (a) is being processed wholly or partly by means of equipment operating automatically in response to instructions given for that purpose; (b) is recorded with the intention that it should wholly or partly be processed by means of such equipment; or (c) is recorded as part of a relevant filing system or with the intention that it should form part of a relevant filing system (section 4). This Act applies to 'any person who processes' and 'any person who has control over or authorizes the processing of, any personal data in respect of commercial transactions (section 2). Processing is defined as "collecting, recording, holding or storing the personal data or carrying out any operation or set of operations on the personal data".

In respect of e-commerce business, there are seven principles that a personal data user (online seller) must abide under the Act. Firstly, the general principle is that the data user must not process the personal data of the data subject (online buyer) without the consent of the latter. Notwithstanding this, a data user may proses personal data if it is necessary for the performance of a contract of which the data subject is a party to, he has taking steps to ask consent from the data subject and for the compliance of any legal obligations in which the data user is a subject thereto (section 6). Secondly, notice and choice principle (section 7). The data user shall by written notice inform a data subject that the latter's personal data is being processed by the data user, its description and purpose of the process and inform the data subject that he has the right to request access and correction of his personal data. The written notice shall be given as soon as practicable by the data user. The third principle is disclosure principle (section 8). It requires that the personal data of a data subject shall not be disclosed without the consent of data subject for any purpose not connected with the purpose in which the personal data was collected. Security principle (section 9) requires the data user to take practical steps to protect the personal data from any loss, misuse, modification, unauthorized or accidental access or disclosure, alteration or destruction. Security measures such as to apply firewalls, 
use logging system, use secure access method, such as a Virtual Private Network (VPN) and passwords could be adopted (Water ISAC Security Information Center, 2015). The data user must take any security measures to be incorporated into any equipment in which the personal data is stored and to take reasonable steps in ensuring compliance with those measures. The fifth principle is retention principle in which it provides that the personal data shall not be kept longer than is necessary for the fulfilment of that purpose. The data user is under a duty take all reasonable steps to ensure that all personal data is destroyed or permanently deleted if it is no longer required for the purpose for which it was to be processed (section 10). Next is the data integrity principle (section 11). The principle demands a data user to take reasonable steps to ensure that the personal data is accurate, complete, not misleading and kept up-to-date. Lastly, the access principle allows a data subject to be given access to his personal data held by a data user and be able to correct that personal data where the personal data is inaccurate, incomplete, misleading or not up-to-date (section 12).

\section{E. Digital Signature Act 1997}

A digital signature is the term used for marking or signing an electronic document, by a process meant to be analogous to paper signatures, but which makes use of a technology known as public-key cryptography (Entrust (Securing Digital Identities \& Information), 2003). Digital signatures are the most effective, secure, and easy-to implement method of providing accountability while enabling electronic transactions. the digital signature process may include a) capturing the entire context of the electronic transaction or document, and precisely what the signer is committing to; $b$ ) ensuring that the data displayed to the user accurately reflects the data to be digitally signed; $c$ ) requiring the user to signal an understanding of the commitment being made, and a desire to be bound to this; d) authenticating the user in order that the user's private key becomes available to the signing device; e) computing the signature based on the signer's private key and the data being signed; f) a timestamp server optionally appending a time-date field to the data and signer's signature and then signing; and g) forwarding the signed transaction for processing, storage, or subsequent verification. Digital Signature Act 1997 was enacted to regulate the use of, digital signatures in Malaysia. 'Digital signature" is defined as 'a transformation of a message using an asymmetric cryptosystem such that a person having the initial message and the signer's public key can accurately determine'. The electronic document signed using digital signature is considered as legally binding document. The Act was amended in 2001 in order to strengthen and encourage future use of digital signatures in electronic transaction. The requirement under the Act is that a certification authority must obtain a license under the Act before they could operate as one. Both certification authority and subscribers to certification are under a duty to ensure that they are using a trustworthy system to create a private key. The functions of a digital signature are these. One, by typing a name, or clicking on a button, or writing a unique sequence of characters, or using secure electronic signatures, a signatory demonstrates his intention to adopt the content of the document. Two, the digital signature indicates to the identification of the signatory and three, it provides for the protection of the integrity of the data where the application of a signature supposedly prevents the tampering of the contents of the document (Kadir, 2012). 


\section{F. Electronic Commerce Act 2006}

Electronic Commerce Act 2006 is an Act to provide for legal recognition of electronic messages in commercial transactions, the use of the electronic messages to fulfill legal requirements and to enable and facilitate commercial transactions through the use of electronic means. The application of the Act extends to private electronic commercial transactions including commercial transactions by the Federal and State Governments. This Act reiterates that any contract formed by an electronic message; communication of offer, acceptance and revocation, is valid and enforceable in law (section 7). Section 9 affirms that a digital signature is reliable as one if (a) is attached to or is logically associated with the electronic message; (b) adequately identifies the person and adequately indicates the person's approval of the information to which the signature relates; and (c) is as reliable as is appropriate given the purpose for which, and the circumstances in which, the signature is required. The Act also states of the continuity of the Digital Signature Act 1997 in respect of any digital signature used as an electronic signature in any commercial transaction.

\section{Legal Issues in Online Business}

\section{A. Completion of Communication of Offer and Acceptance}

Where an offer is made through social media and its acceptance is required of the same platform, the issue is when does communication of offer and acceptance completed? The postal rule in the Contracts Acts suggests that the communication acceptance is complete when the offer is made through letters or instantaneous means of communication (telegram or fax), the acceptance is complete as soon as it is posted (section 4 Contracts Act 1950) (Henthorn V. Fraser. [1892] 2 Ch. 27). The same rule could not easily apply in social media platform as acceptance would not be physical in nature. Therefore, understanding on how data transmission on internet or mobile internet works would provide certain degree of certainty on when communication of acceptance occurs. Data transmission through online platform involves three summarized steps. Firstly, a data from an information source (a computing device) is transmitted to a central broadcast server. Secondly, the central broadcast server will preprocessed the said data and lastly, the preprocessed data is transmitted to receivers of the said computing device. It will then instantaneously notify the said computing devices of receipt of said preprocessed data whether said computing devices are on or off (Katz, et al., 2000). The communication of acceptance is then completed. This process is consistent with article 15 of the UNCITRAL Model Law on e-Commerce 1996 that states "the dispatch of a data message occurs when it enters an information system outside the control of the originator". It means that, when the seller receives a message stating the intention of the potential buyer of his/her agreement to accept the offer, the communication of acceptance is completed.

\section{B. Quality of goods}

One of the issues that arise is in respect of the quality of the goods. In an e-commerce transaction, it is not possible for the buyer to examine the goods before buying them. What they can do is to read the description provided by the seller such as in the websites or in the seller's social media or mobile social platform. For established e-commerce companies such as Zalora, Lazada and 11street (to name a few), the customer can always return the goods after the purchase (usually within 7 days of the purchase) and the company will refund the money by way of crediting the amount into the 
customer's account. However, in social media or mobile media platform, this feature is not normally provided. In fact, some sellers may refuse to accept the return of the goods and remedy the same. In Wee Lian Construction Sdn Bhd V. Ingersoll-Jati Malaysia Sdn Bhd [2010] 4 CL 203, the Court of Appeal held that the law allows a purchaser to examine the goods delivered to him. Therefore, if a purchaser has examined the goods and accepted them, he cannot reject them after a reasonable time. In another case of Universal Cable (M) Bhd V. Bakti Arena Sdn Bhd \& Ors [2000] 3 CLJ 375, the court held that if a purchaser accepts delivery of the goods and within reasonable time does not intimates to the seller that the goods are not in conformity with the specifications, quantity, time and price as set out in the purchase orders, the purchaser had lost its right to reject those goods. Product labelling and safety warnings are also omitted by the online sellers (OECD, 2013). Products that involve safety features such as children car seat, baby carrier, rocker etc. are sold rampantly without proper safety warnings. Some do not even meet the mandatory safety standards.

The Guidelines for Control of Cosmetic Products in Malaysia (2008) and Guidelines for Control of Cosmetic Products in Malaysia-1st Revision Annex I (2017) (Anon., 2017) provide certain guideline to cosmetic products. The product description must contain ingredients of the product, instruction for its use and disposal warning statements. The raw materials used must comply with the national legislation standards on chemicals or dangerous substances and if a safety claim is to be made, it has to be supported by adequate evidence. The manufacturers must comply with the requirements under these statutes, namely the Poison Act 1952 and Dangerous Drugs Act 1952, Control of Drugs and Cosmetic Regulation 1984 (Kamarulzaman, n.d.). For food products including baby food and products that are allegedly helps children growth and brain development, they must comply with the Food Act 1983. Nowadays, chemical products including cosmetic and food products are sold rampantly online without necessary adherence to the national legislations. Fancy advertisements with over claimed statement cause the consumer to be easily misled.

\section{Non-display of Price}

From the authors' observation on internet, most online sellers with a brand name or patent, has comply with the 2012 Regulation in respect of the name of the business, product description, price and method of payment. However as for the requirement to state the price, sellers using social media and mobile media often omit to state the price of their product. The interested buyer will have to message the seller privately in order to know the price of the product advertised. Some are reluctant to give details of the product they are selling (New Straits Times, 2017). The price tagging is a requirement under the 2012 Regulation and the Price Control Order (Indication of Price by Retailer) 1993. Failure to disclose the foregoing information is an offence. With the application of CPA and the 2012 Regulation to e-commerce business, the online buyers may now lodge their complaints to the Tribunal for Consumer Claims. The jurisdiction of the Tribunal is in respect of any matters provided by the CPA and where the total amount claimed does not exceed RM25, 000.00. In addition to that, online sellers who fail to comply with the 2012 Regulations commits an offence, where the case shall be heard and tried by a Magistrates Court. 


\section{Privacy}

E-commerce has always faces with security and privacy issue. There are two issues in dealing with ecommerce security strategies, namely "protecting the integrity of the business network and its internal systems; and with accomplishing transaction security between the customer and the business" (Marchany \& Tront, 2002). The threats can come from hackers, computer viruses and abuse of customer's private information. Methods of payment for purchases done online varies from credit card channel (VISA, Mastercard, Amex), internet banking (Maybank2u, CimbClick, HongLeong connect), e-wallet (Alipay, Wechat Pay, MOL-Wallet) and payment over the counter (MOLPay Cas). Most of these methods involve buyer providing their personal data; name, address, email address, phone number and bank card or credit card number. Inevitably, the personal data of a customer becomes exposed online. Without a proper security features and firewalls, these information may be hacked by other people. Security features such as authentication, authorization, encryption, integrity, nonrepudiation, authenticity, confidentiality, privacy and availability protects the information from being modified by unauthorized person and ensure that the data is kept hidden especially when using internet banking system (Revathi C, 2015) (Ghayoumi, n.d.) (Mohamed \& Zeki, 2015). The consumers' concern on privacy issues include fear of unauthorized access to personal data including security breaches and the risk of secondary use including data sharing with a third parties who are not part of the transaction (Ackerman \& Davis, 2003).

The implementation and enforcement of personal data protection laws are oversees by a Personal Data Protection Commissioner which is appointed by a Minister from the Ministry of Information, Communication and the Arts Malaysia (section 47). The Commissioner sits in the Department of Personal Data Protection at the Ministry. The Commissioner has an administrative duty to decide whether there is a serious breach of personal data protection principles under the Act. An individual may make a complaint in writing to the Commissioner about an act, practice or request of a data user which may be a contravention of the provisions of this Act (section 104). Upon receiving the complaint, the Commissioner may initiate an investigation to determine the matter. Following the completion of an investigation, the Commissioner may, if he is of the opinion that the complained data user is contravening the Act, serve the data user an enforcement notice under section 108 specifying the breach. The Commissioner may later appoint an authorized officer to exercise the powers of enforcement under the Act. The decision specified in the enforcement notice can be challenged by filing a notice of appeal with the Appeal Tribunal. A decision of the Commissioner is not final. An aggrieved party may appeal to the Appeal Tribunal whose decision is final and binding on the parties to the appeal.

\section{Islamic Online Business}

Islamic e-business can be defined as the practice of performing and coordinating critical business processes through the use of computer and other technologies that to better reflect the Islamic point of view (Amin, 2008). Indeed, Islamic e-business can also be defined as using electronic facilities in order to conduct business transactions electronically. Islam accepted online businesses for individual person as long as it is conducted in line with Islamic principle. . The following verse of al-Quran presents an argument on the permissibility of online business in Islam: 
“...Allah has permitted trade and forbidden usury. Those who after receiving direction from their Lord, desist, shall be pardoned for the past; their case if for God; but those who repeat the offence are Companions of the Fire; they will abide therein forever (2:275)"

There is also another verse which emphasized on the importance of recording transactions: "O you who believe! When you deal with each other, in transactions involving future obligations in a fixed period of time, reduce them to writing... $(2: 282) "$

The permissibility is also highlighted by the Prophet Muhammad S.A.W, which can be read as follows: "A sale for a deferred payment by installment is good"

All of the above verses provide general guidelines for Muslim in conducting their business electronically. Addition to that, there is also certain conditions which was highlighted to ensure the legality of e-commerce in Islam. First, there should be clarity in the communication and the products offered must be clearly defined. For example, the pictures of the products must be clearly displayed on the screen, give detailed specifications, the prices, the mode of delivery and the mode of payment must be clearly stated. Second, both contracting parties must receive the message in order to achieve conformity in the agreement (concluding the contract). The same message should be informed to all the contracting parties. Third, there must be continuity in the communication, whether in the transmission of message or in consulting between one another via e-mail (Zainul.N, et al., 2004).

All in all, the basic principles of Islamic business must be observed especially the prohibition of interest (riba), regardless of its form or source. The practice of riba will lead to the wealth concentration in the hand of few and neglect the others. In more detail, the following provides the legality of Islamic e-business:

\section{Legality of goods or services offered}

The parties in Islamic online business must ensure that they complied with the requirements that mentioned in Quran and Sunnah on the goods or services that can be transacting among Muslims. It is, thus important to ensure that the commodity and service must be permitted by the Shariah to be transacted. Thus, any non-halal goods or services must be avoided as they against the true spirit of Islamic business. Besides that, sellers are also need to describe its services and products precise and clear to avoid any ambiguity which can cause misunderstanding between the parties in the contract.

\section{Medium of communication}

A transaction that is implemented electronically must have clarity in the communication. Since online business is using electronic medium as a way of communication, it is important to always caution with the transaction. It is thus; better to put everything in writing, either through email or mobile phone. It is important to note that, a constant communication is able to reduce doubt by many transacting parties on the use of Islamic online business. 


\section{Delivery of good}

It is also a condition to ensure that the products to be bought by a customer must be delivered at the promised date in order to make sure it is free from deceit and fraud. By having all this matter in mind, it is reasonable to conduct online business from Islamic viewpoint but, it does not mean that everything from conventional is not fit. As long as it does not violate all the Islamic principles; it is then permissible.

\section{Conclusion}

There is no doubt that Malaysian government is stepping forward by enacting new laws and regulations governing online businesses in electronic commerce. Even though protection is afforded to online consumers under various pieces of legislation, it does not comprehensively deal with adequate and sufficient protection. Thus, there is a need to draft and enact ONE comprehensive legislation on electronic commerce, its protection to consumer as well as the buyer and the penalty for those who against the law.

\section{Corresponding Author}

Maheran Makhtar, Universiti Sultan Zainal Abidin, Department of Law, Faculty of Law and International Relations, 21300 Kuala Nerus, Terengganu, Malaysia,

Email: maheranmakhtar@unisza.edu.my

\section{References}

Ackerman, M. J. \& Davis, D. (2003). Privacy and Security Issues in E-Commerce. Elsevier Science.

Amin, H. (2008). E-Business from islamic perspectives: prospects and challenges, December 2008,. s.l.:Journal of Internet Banking and Commerce.vol. 13, no.3, pp. 2.

Ding, J. (1999). E-Commerce:Law and Practice. Malaysia: Sweet \& Maxwel Asia.

Entrust (Securing Digital Identities \& Information) (2003). Digital Signatures - Best Practice for eBusiness Transactions, United State \& Canada: https://www.entrust.com/wpcontent/uploads/2013/05/digsig_transactions.pdf.

Kadir, R. (2012). Malaysian DSA 1997: A Review of Some Unresolved Issues. Asian Social Science. Canadian Center of Science and Education., 8(12).

Kandiah, S. (2016). Malaysia. The Privacy, Data Protection and Cybersecurity Law Review. In: Law Business Research Ltd. 3rd.edition. s.I.:s.n., p. 229.

Mohamed, A. A. \& Zeki, M. (2015). The most principle Security Issues In E-commerce. International Journal of Scientific and Research Publications, 5(2). 
New Straits Times (2017). Pm, please: Why are Online Sellers Still Not Revealing Prices of Items for Sale? , s.I.: https://www.nst.com.my/news/nation/2017/08/263670/pm-please-why-are-onlinesellers-still-not-revealing-prices-items-sale.

OECD, (2013). Online Product Safety: Trends and Challenges, Paris: OECD Digital Economy Papers, OECD Publishing.

Parsons, A. (2002). Non-Functional Motives for Online Shoppers: Why We Click. Journal of Consumer Marketing, 19 (5), pp. 25-39.

Revathi, C. S. (2015). A Study on E-Commerce Security Issues. International Journal of Innovative Research in Computer and Communication Engineering, 3(12).

Water ISAC Security Information Center, (2015). 10 Basic Cybersecurity Measures Best Practices to Reduce Exploitable Weaknesses and Attacks, s.l.: https://ics-cert.uscert.gov/sites/default/files/documents/10_Basic_Cybersecurity_MeasuresWaterISAC_J.

Zainul, N., Osman, F. \& Mazlan, S. H. (2004). E-Commerce from an Islamic Perspective. Electronic Commerce Research and Application (Elsevier), Volume 3, pp. 280-293. 